\title{
Research article \\ Correlation of CA 19-9 with HbA1c in prediabetic and diabetic groups
}

\author{
Pratheeksha, Vinod Chandran, Gayathri M. Rao, Durga Rao
}

Department of Biochemistry, Kasturba Medical College Mangalore, Manipal Academy of Higher Education, Manipal, Karnataka, India

(Received: October 2021

Revised: November 2021

Accepted: November 2021)

Corresponding author: Vinod Chandran. Email: vinod.chandran@manipal.edu

\begin{abstract}
Introduction and Aim: Carbohydrate antigen19-9 (CA 19-9) is a marker of pancreatic cancer. In diabetics, pancreatic beta cell dysfunction can lead to elevated serum CA19-9 level. This study was designed for estimation of CA19-9 in diabetes and its correlation with glucose levels and glycosylated hemoglobin.
\end{abstract}

Materials and Methods: The includes diabetic, pre diabetic with no history of malignancies and healthy normal subjects ( $\mathrm{n}=50$ each). Ca19-9 was estimated using ELISA, HbA1c by D10-Biorad variant turbo and the Lipid profile in Roche COBAs 6000 auto analyzer. Statistical analysis was done by Statistical Package for Social Sciences software version 17 (SPSS 17). P <0.05 was considered significant.

Results: Serum CA19-9 level was high in diabetics compared to normal, $(\mathrm{p}=0.38$ ) however it was decreased in pre diabetic group $(\mathrm{P}=0.06)$. There was significant difference in comparison of CA19-9 levels between pre diabetic and diabetics $(\mathrm{p}=0.001)$. A significant increase in triglycerides was observed both in diabetics $(\mathrm{p}<0.01)$ and prediabetics $(\mathrm{p}=0.04)$. There was a significant positive correlation of CA19-9 with TC/HDL $(\mathrm{p}=0.022)$ and non-HDL $(\mathrm{p})$ in control group.

Conclusion: CA19-9 levels can be influenced by glycemic status, hence assessment of pancreatic cancer in diabetic patients must be interpreted carefully in consideration with CA19-9 levels. CA19-9 level was decreased in prediabetics when compared to normal and diabetics. This is a novel finding, the cause for which must ascertained, and this will open further avenues for research.

Keywords: CA 19-9; pancreatic cancer; diabetes; pre-diabetic; lipid profile; HbA1c.

\section{INTRODUCTION}

$\mathrm{D}$ iabetes mellitus is a cluster of metabolic syndromes in which the capability to produce insulin is reduced and results in hyperglycemia, which leads to the signs such as frequent urination, increased thirstiness, and hunger and further to several secondary consequences. It can be either severe complications such as diabetic acidosis, non-ketotic hyperosmolar coma or serious long-term complications such as cardiac disease, stroke, chronic kidney disease, foot ulcer and damage to the eyes. Diabetes may occur due to the decreased insulin production by the exocrine gland as in type-1or the cellar defect to respond to the produced insulin as seen in type-2. Pre-diabetic condition can lead to type 2 diabetes if there is a defect in lifestyle modification. Deficiency of Insulin affects the key enzymes and metabolic pathway of lipid and can cause dyslipidemia. Diabetic mellitus can be a risk factor for pancreatic, hepatic duct, breast, ascending tract, and rectal cancer (1).

$\mathrm{HbA1C}$ has been a reliable indicator of long-term glycemic control $(2,3)$. Non-enzymatic glycation pathway can lead to the formation of glycated hemoglobin on exposure to plasma glucose. Glycated hemoglobin concentration increases in response to the increased levels of average plasma glucose. All these can be a reason for the increased production of free radical and altered metabolic reactions and consequences such as alter the RBC cell membrane integrity leading to the aggregation of blood cells and viscosity.

CA 19-9, a carbohydrate antigen is thought to be sialylated Lewis (Le)a blood group antigen, identified by a murine monoclonal antibody against a colorectal carcinoma antigen, is a diagnostic marker for the pancreatic tissue damage which is also elevated in pancreatic cancer (4). An elevation in CA19-9 was also found in various other cancers like, ovarian, hepatocellular, and colorectal cancer. This antigen was also found to be elevated in certain inflammatory conditions, obstruction of biliary tract and in diseases affecting thyroid gland $(5,6)$. Another condition where this marker is implicated is cystic lung disease and in pulmonary sequestration $(7,8)$. High serum CA19-9 levels were also found in patients with microvascular complications of diabetes (9).

Type 2 diabetes mellitus usually associated with dyslipidemia, which in turn because of increased triglycerides in beta cells of pancreas may lead to cell death $(10,11)$. Significant correlations were observed between CA19-9, pancreatic cell function and cholesterol levels in diabetics. The accumulation of cholesterol in the cells can have effects on islets which secrete insulin. This result in impaired secretion of insulin. This could be a key factor in the progression 
of diabetes. Excess cellular cholesterol plays a direct role in islet pancreatic beta cell dysfunction and may be a key factor underlying the progression of type 2 diabetes. The relation between increased serum cholesterol and the corresponding increase in pancreatic islets was demonstrated using some animal studies $(10,11)$

\section{MATERIALS AND METHODS}

\section{Study design}

A cross sectional study was conducted over a period of three months after obtaining approval by the Institutional ethics committee (IEC KMC MLR 1217/28).

\section{Study population}

Subjects were divided into 3 groups based on the glucose values, 50 cases of prediabetic, 50 cases of diabetic and 50 of normal control, samples obtained in clinical biochemistry section of KMC Laboratory Services (KMCLS), situated at KMC Hospital Ambedkar Circle (KMCHAC), Mangalore, Karnataka, India.

\section{Inclusion criteria}

Subjects diagnosed with pre-diabetic (FBS: 101-125 mg/dl/, PPBS: 140-200 mg/dl), diabetic (FBS>126 $\mathrm{mg} / \mathrm{dl} / \mathrm{PPBS}>200 \mathrm{mg} / \mathrm{dl}$ ) of either sex of duration 520 years. Normal healthy controls (FBS70-100mg/dl/ PPBS $<125 \mathrm{mg} / \mathrm{dL})$.

\section{Exclusion criteria}

Known cases of pancreatic, ovarian, hepatocellular, and colorectal cancer. Duration of diabetes $<5$ years and $>20$ years.

\section{Methods}

1. Estimation of CA19-9 done by Solid phase enzyme-linked immunosorbent assay (ELISA) in ELX 800 by BIO TEK® Instruments, Inc.

2. Estimation of plasma glucose by Cobas c- 6000 by hexokinase method.

3. HbA1C estimation by - D10 Bio-Rad variant II turbo by using ion- exchange highperformance liquid chromatography (HPLC).
4. Cholesterol estimation by CHOD-POD, triglycerides by GPO-PAP, HDL and LDL by direct enzymatic method.

\section{Estimation of CA19-9 (Carbohydrate antigen 19-9)}

The samples were analyzed in the Department of Biochemistry, Center for Basic Sciences, KMC, Bejai, Mangaluru. The CA19-9 ELISA test is an adapted solid phase sequential sandwich ELISA. Samples and biotinylated monoclonal antibody are added to the wells coated with streptavidin. CA19-9 in the patient sample binds to biotinylated capture antibody. The biotinylated antibody simultaneously binds to the streptavidin coated plate. After a wash step, antiCA19-9-HRP enzyme conjugate is added and forms a sandwich around captured CA19-9. Unbound antibodies are washed off. TMB substrate is added resulting in the development of blue color. The concentration of CA19-9 is directly proportional to the color intensity developed. A standard curve is generated relating color intensity to CA19-9 concentration.

\section{Statistical analysis}

Sample size was calculated using the following formula-

$$
n=\frac{2(Z \alpha+Z \beta)^{2} * \sigma^{2}}{\mathrm{~d}^{2}}
$$

$\mathrm{Z} \alpha=1.96$ at $95 \%$ confidence level

$\mathrm{Z} \beta=0.84$ at $80 \%$ power

$\sigma=$ combined standard deviation

$\mathrm{d}=$ mean difference between group

$\mathrm{n}=$ sample size $(50)$

\section{Data analysis}

Data analysis was performed in Statistical Package for Social Sciences software version17 (SPSS 17). Continuous variables were expressed as mean \pm SD / SEM. Group comparisons were done by using Oneway analysis of variance (ANOVA)followed by posthoc Tukey's multiple comparison test. Categorical variables were computed by using chi-square test. Spearman's correlation coefficient test also used. Significance was considered when $\mathrm{p}<0.05$.

Table 1: Clinical characteristic and tumor marker level comparison between type 2 diabetic, pre-diabetic, and normal control.

\begin{tabular}{|c|c|c|c|c|c|c|}
\hline Parameters & $\begin{array}{c}\text { Control } \\
\mathbf{n = 5 0}\end{array}$ & $\begin{array}{c}\text { Prediabetes } \\
\mathbf{n = 5 0}\end{array}$ & $\begin{array}{c}\text { Diabetes } \\
\mathbf{n = 5 0}\end{array}$ & P1 & P3 \\
\hline $\begin{array}{c}\text { Age(year) } \\
\begin{array}{c}\text { Gender [male: female] } \\
(\%)\end{array}\end{array}$ & $35: 15(70: 30)$ & $32: 18(64: 36)$ & $37: 13(74: 26)$ & & & \\
\hline $\begin{array}{c}\text { Diabetes duration } \\
\text { (years) }\end{array}$ & - & - & $12.12 \pm 5$ & - & $<0.01^{*}$ & $0.04^{*}$ \\
\hline FBS (mg/dl) & $95 \pm 4.01$ & $111 \pm 9.35$ & $186 \pm 51$ & $0.02^{*}$ & $<0.001^{*}$ & $<0.001^{*}$ \\
\hline HbA1c(\%) & $5.2 \pm 0.18$ & $6.02 \pm 0.3$ & $9.32 \pm 2.31$ & $0.01^{*}$ & $<0.001^{*}$ & $<0.001^{*}$ \\
\hline CA 19-9(U/ml) & $17.37 \pm 2.23[11$ & $\begin{array}{c}9.7 \pm 1.72 \\
(19.72)]\end{array}$ & $\begin{array}{c}21.86 \pm 3.04 \\
{[6.16(10.49)]}\end{array}$ & 0.06 & 0.38 & $0.001^{*}$ \\
\hline
\end{tabular}




\begin{tabular}{|c|c|c|c|c|c|c|}
\hline TC $(\mathrm{mg} / \mathrm{dl})$ & $178 \pm 38$ & $180 \pm 45$ & $184 \pm 58$ & 0.96 & 0.80 & 0.91 \\
\hline TG $(\mathrm{mg} / \mathrm{dl}){ }^{@}$ & $\begin{array}{c}130 \pm 7.95 \\
{[126.5(82.25)]}\end{array}$ & $\begin{array}{c}145 \pm 16.16 \\
{[119(61.25)]}\end{array}$ & $\begin{array}{c}197 \pm 19.68 \\
{[153(92.75)]}\end{array}$ & 0.78 & $<0.01^{*}$ & $0.04 *$ \\
\hline HDL-C (mg/dl) & $43.59 \pm 12.1$ & $47 \pm 11.48$ & $42.5 \pm 10.83$ & 0.27 & 0.90 & 0.11 \\
\hline LDL-C (mg/dl) & $124 \pm 38$ & $158 \pm 248$ & $123 \pm 53$ & 0.48 & 0.99 & 0.46 \\
\hline TC/HDL (mg/dl) & $7.13 \pm 19.95$ & $4.02 \pm 1.32$ & $4.50 \pm 1.73$ & 0.37 & 0.49 & 0.97 \\
\hline VLDL (mg/dl) ${ }^{@}$ & $30 \pm 4.5$ & $29 \pm 3.23$ & $39 \pm 3.94$ & 0.97 & 0.23 & 0.15 \\
\hline Non-HDL (mg/dl) & $131 \pm 41$ & $133 \pm 44$ & $141 \pm 54$ & 0.95 & 0.52 & 0.71 \\
\hline
\end{tabular}

All results were expressed in Mean \pm SD (Standard deviation).

*Indicates significant difference at $\mathrm{p}<0.05$ P1 $=$ Control vs Prediabetes, $\mathbf{P 2}=$ Control vs Diabetes and P3 $=$ Prediabetes vs Diabetes comparisons, $\$$ indicates Chi-square p-value $\mathbf{= 0 . 5 5}$

@ Results were expressed as Mean \pm SEM (Standard Error of Mean)

Values in the [ ] were median and interquartile range of the variables

Table 2: Correlation of CA19-9 with glycemic profile

\begin{tabular}{|c|c|c|c|c|}
\hline Parameter & Correlation & Control & Prediabetic & Diabetic \\
\hline \multirow{2}{*}{ FBS } & $\mathrm{r}$ & -0.154 & .009 & .093 \\
\cline { 2 - 5 } & $\mathrm{p}$ & .284 & .951 & .520 \\
\hline \multirow{2}{*}{ HbA1c } & $\mathrm{r}$ & 0.047 & -0.002 & 0.187 \\
\cline { 2 - 5 } & $\mathrm{p}$ & 0.748 & 0.991 & 0.192 \\
\hline
\end{tabular}

Significance was observed between the normal and diabetic patients(P1) in: age, FBS, HbA1c and TG. In the lipid profile only, TG has a significance with CA19-9 in Normal and Diabetic(P2) and Diabetic and pre-diabetic. CA19-9 levels are increased in diabetes, and are decreased in pre-diabetics, when compared to normal. A statistically significant increase in CA 19-9 level (Table1) was observed in diabetic group when compared with pre-diabetic group. CA19-9 was

Table 3: Correlation of CA19-9 with lipid profile

\begin{tabular}{|c|c|c|c|c|}
\hline Parameter & Correlation & Control & Pre-diabetic & Diabetic \\
\hline TC & $\mathrm{r}$ & 0.269 & 0.118 & 0.067 \\
\hline & $\mathrm{p}$ & 0.059 & 0.416 & 0.643 \\
\hline TG & $\mathrm{r}$ & 0.267 & -0.042 & 0.134 \\
\hline & $\mathrm{p}$ & 0.061 & 0.771 & 0.353 \\
\hline HDL & $\mathrm{r}$ & -0.171 & 0.052 & -0.014 \\
\hline & $\mathrm{p}$ & 0.234 & 0.719 & 0.923 \\
\hline LDL & $\mathrm{r}$ & 0.262 & 0.163 & 0.006 \\
\hline & $\mathrm{p}$ & 0.066 & 0.257 & 0.969 \\
\hline TC/HDL & $\mathrm{r}$ & 0.323 & 0.117 & 0.107 \\
\hline & $\mathrm{p}$ & 0.022 & 0.419 & 0.461 \\
\hline VLDL & $\mathrm{r}$ & 0.200 & -0.042 & 0.136 \\
\hline & $\mathrm{p}$ & 0.163 & 0.771 & 0.347 \\
\hline Non-HDL & $\mathrm{r}$ & 0.298 & 0.174 & 0.99 \\
\hline & $\mathrm{p}$ & 0.035 & 0.227 & 0.493 \\
\hline
\end{tabular}

The Values of TC $(r=0.269, \mathrm{p}=0.059)$, TC $/ \mathrm{HDL}$ $(\mathrm{r}=0.323, \mathrm{p}=0.022)$, non-HDL $(\mathrm{r}=0.298, \mathrm{p}=0.035)$ positively correlated with CA 19-9.

\section{DISCUSSION}

Difference in the levels of CA19-9 was observed when diabetic group was compared with both normal and pre-diabetic subjects. This agrees with the previous studies. Previous reports have shown that patients with poor metabolic control have increased CA19-9 levels. But these levels were found to decrease after successful control (12). In our study the maximum CA19-9 value $(89 \mathrm{U} / \mathrm{ml})$ was observed in diabetic negatively correlated with FBS and positively correlated with $\mathrm{HbA1c}$ in control group. In prediabetic HbA1c has negative correlation with CA199. In diabetic group both FBS and HbA1c shows positive correlation (Table2) A significant positive correlation of TC /HDL with CA19-9 observed in normal group. In pre-diabetic, TG and VLDL has negative correlation were as in diabetic HDL has negative correlation (Table 3 ). patients. Although CA19-9 is pancreatic cancer marker, higher than normal serum CA19-9 values, can be found in non-malignant conditions also (5-8) Few studies have shown increase in CA19-9 in diabetics compared to normal (1) The present study findings also in agreement with these studies. Interestingly, we observed a dip in CA19-9 levels in pre-diabetics when compared with that of normal. However, there was a positive correlation of CA19-9 with FBS values in diabetic and pre-diabetic patients and negative correlation with $\mathrm{HbA} 1 \mathrm{c}$ values. 
One of the previous studies reported a significant positive correlation between serum CA19-9 levels and $\mathrm{HbA1c}$ (13). These findings are in agreement with our study also. It remains unclear how CA19-9 is elevated in diabetics. CA19-9 is expressed by the exocrine pancreas, so one possible reason for this elevation is could pancreatic exocrine deficiency triggered by insulin deficit and release of CA19-9 by the ductal cells $(14,15,16)$. The elevated levels of CA19-9 may point out exocrine dysfunction. Further, contacts between exocrine and endocrine cells are direct since they are void of capsules or basement membranes around islet cells. Because of the direct connection between the islets and acinar cells by the capillaries that bring about the regulatory connections between islet hormones and exocrine pancreatic secretion, insulin directly enters the acinar cells. It also assumed that CA 19-9 levels show some communication between the exocrine and endocrine pancreatic cells. Therefore, hyperglycemia may have some detrimental effects on the exocrine pancreas in addition to the endocrine pancreas as demonstrated by the significant elevation of CA 19-9 in diabetic individuals than nondiabetic / pre-diabetic individuals. Furthermore, there was a non-significant positive correlation between CA 19-9 levels and FPG in patients with DM. Hyperglycemia being an independent factor for mortality rate of an individual because of its consequences and impact on cellular or metabolic impairment, including the exocrine tissues and this could be the major contributing factor in CA 19-9 secretion. This is because dropped blood glucose levels improved exocrine pancreatic dysfunction (17).

Diabetes is usually associated with dyslipidemia (18). An increased TC can decrease pancreatic beta cell function contributing to CA19-9 increase. In our study CA-19-9 was positively correlated with TC levels. However, the correlation was not significant. One of the previous studies reported that the HOMA-IR index is a contributing factor in the changes of serum levels of CA19-9 after the rapid metabolic control by Rouxen-Y gastric bypass (19). Therefore, serum levels of CA19-9 might be an effective indicator of Insulin resistance, glycemic index, and lipid metabolism in patients with obesity and type 2 diabetes. This could be one of the explanations to the decreased levels of CA19-9 observed under pre-diabetic condition during the study. A study by Masanori et al., (20) in normoglycemic and prediabetic subjects reported that an increase in serum CA 19-9 levels may reflect the extent of insulin secretion disorders among prediabetic individuals. However, the present study showed a dip in CA19-9 level in pre diabetic subjects i n comparison with normal controls. This is a novel finding in the study and yet to reveal the causative factor, it is well known that the Lewis (FUT3) and Secretor (FUT2) genes regulate CA 19-9 secretion (21-23). However, the study by Zhaoyang et al., (24) does not support the hypothesis that circulating CA19-
9 has a causal effect on diabetes risk, and CA19-9 might be a potential biomarker of incident diabetes mellitus risk.

\section{CONCLUSION}

We estimated that serum levels of CA19-9 which were elevated in diabetic patients without malignancy. Overall, the study indicates that levels of this tumor marker should be interpreted carefully in diabetic patients. CA19-9 level was decreased in pre-diabetic compared with that of normal and may open a new avenue for further studies with larger sample sizes to validate the underlying mechanisms.

\section{CONFLICT OF INTEREST}

Authors declare that there is no conflict of interest.

\section{REFERENCES}

1. Moodahadu, S. L., Dhall, R., Zargar, H. A., Bangera, S., Ramani, L., Katipally, R. Tight Glycemic control and cardiovascular effect in type 2 diabetic patients. Heart views. J of Gulf Heart Association. 2014; 15(4): 111-112.

2. SaudeK, D. C., Brick, C. J. The clinical use of hemoblobinA1c. J Diabetes Sci Technol. 2009; 3(4): 629634.

3. Murai, J., Soga, S. Saito, H., Otsuki, M., Kitada, T., Saisho, Y., et al., Study on the mechanism causing elevation of serum CA19-9 levels in diabetic patients. Endocrine Journal .2013; 60(7): 885-891.

4. Gul, K., Nas, S., Ozdemir, D., Gumus, M., Ersoy, R., Cakir, B. CA 19-9 level in patients with type 2 diabetes mellitus and its relation to the metabolic control and microvascular complications. The American journal of the Medical Sciences. 2011: 341(1); 28-32.

5. Uygur, B, O., Dabak, R., Orbay, E., Dolapcioglu, C., Sargin, M., Kilicoglu, G., et al., Type 2 diabetes and CA19-9 levels. World J Gastroenterol. 2007; 13(40): 5357-5359.

6. Shang, X., Song, C., Wang, X. The serum level of tumor marker CA19-9, CEA, CA72-4 and NSE in type 2 diabetes without malignancy and the relations to the metabolic control. Saudi Med J. 2017; 38(2): 204-208.

7. Jiajia, D., Yijing, C., Ruicong, C., Shanjie, D., Yongping, C and Keqing, S. A Case Report and a Short Literature Review of Pulmonary Sequestration Showing Elevated Serum Levels of Carbohydrate Antigen 19-9. J Nippon Med Sch. 2015; 82: 211-215.

8. Ambiru, S., Nakamura, S., Fukasawa, M., Mishima, O., Kuwahara, T. Intralobar pulmonary sequestration associated with marked elevation of serum carbohydrate antigen 19-9. Ann Thorac Surg 2009: 88; 2010-2011.

9. Tong, W., Gao, H., Wei, X., Mao, D., Zhang, L, Chen, Q., et al., Correlation of serum CA199 levels with glycemic control and microvascular complications in patients with type 2 diabetes mellitus. Am J Transl Res. 2021 Apr 15; 13(4): 3302-3308.

10. Ma, M., Liu, H., Yu, J., Shuli, H., Ping Ping, L., Chunxiao, M., et al., Triglyceride is independently correlated with insulin resistance and islet beta cell function: a study in population with different glucose and lipid metabolism states. Lipids Health Dis. 2020; 19 (121). https://doi.org/1 0.1186/s12944-020-01303-w.

11. Hao, M., Head, W. S., Gunawardana, S. C., Hasty A. S., Piston D. W. Direct effect of cholesterol on insulin secretion: a novel mechanism for pancreatic $\beta$-cell dysfunction. J Diabetes. 2017:56 (9); 2328-2338.

12. Shang, X., Song, C., Du, X., Shao, H., Xu, D., Wang, X. The serum levels of tumor marker CA19-9, CEA, CA72-4, and NSE in type 2 diabetes without malignancy and the relations to the metabolic control. Saudi Med J. 2017; 38(2): 204-208. 
13. Ritika, S., Ashutosh, Bhawna, M., Gupta, V. K. Effect of Glycemic Status on Serum CEA and CA 19-9 Levels in Patients of Diabetes Mellitus in Northern India. International Journal of Health Sciences \& Research. 67 (8); 2018: 67-72.

14. Donath, M. Y., Schumann, D. M., Faulenbach, M., Ellingsardh, Perren, A., Ehses, J. A. Islet inflammation in type 2 diabetes, from metabolic stress to therapy. Diabetes care. 2008; 31(2); 161-164.

15. Radlinger, B., Ramoser, G., Kaser, S. Exocrine Pancreatic Insufficiency in Type 1 and Type 2 Diabetes. Curr Diab Rep. 2020; 20(6): 18. Published 2020 Apr 1. doi:10.1007/s11892020-01304-0

16. Manafa, P. O., Okoye, E. C., Ekuma, O., Ukibe, R. N., .Ibe, C., Chukwuma, C. R., et al., Evaluation of carbohydrate antigen 19-9 levels in subjects with diabetes mellitus in NnamdiAzikiwe university teaching hospital, Nnewi, Nigeria. Med J DY Patil Vidyapeeth. 2020; 13: 306-310.

17. Seo, H. A., Kim, E. H. The Difference of CA 19-9 Level among diabetes, prediabetes and healthy control. EndocrSoc J. 2016; 202: 971-976.

18. Minglei, M., Haibin, L., Jie, Y., Shuli, H., Pingping, L., Chunxiao, M., et al., Triglyceride is independently correlated with insulin resistance and islet beta cell function: a study in population with different glucose and lipid metabolism states. Lipids in Health \& Disease. 2020; 19: 121. https:// doi.org/10.1186/s12944-020-01303-w.

19. Roux, E.N.Y., Yinfang, T., Haoyong, Y., Pin, Z., Jianzhong, D., Xiaodong, H., et al., Decreased serum CA19-9 is associated with improvement of insulin resistance and metabolic control in patients with obesity and type 2 diabetes after gastric bypass. J Diabetes Invest. 2014; 5: 694-700.

20. Masanori, S., Tomohiro, N., Koji, N., Mutsuhiro, K., Norinao H., Tomohiro, N. The Relation between CA 19-9 level and early-Phase Insulin Secretion in Normoglycemic and Prediabetic Subjects. The International Journal of Biological Markers.2018; 30(2): 169-173.

21. Luo, G., Guo, M., Jin, K., Liu, Z., Liu, C., Cheng, H., et al., Optimize CA19-9 in detecting pancreatic cancer by Lewis and Secretor genotyping. Pancreatology. 2016; 16(6): 10571062.

22. Meng, G., Guopei, L., Xianjun, Y. Distribution of Lewis and secretor polymorphisms and corresponding CA19-9 antigen expression in a Chinese population. FEBS Open Bio. 2017; 7: 1660-1671.

23. Abe, T., Koi, C., Kohi, S., Song, K. B., Tamura, K., Macgregor, D.A., et al., Gene Variants That Affect Levels of Circulating Tumor Markers Increase Identification of Patients with Pancreatic Cancer. Clin Gastroenterol Hepatol. 2020;18 (5): 1161-1169.

24. Zhaoyang, L., Jing, W., Xu, H., Fei, W., Hua, H., Jing, Y., et al., Association between cancer antigen 19-9 and diabetes risk: A prospective and Mendelian randomization study. Journal of Diabetes investigation. 2019: 11(3): 585-593. 